\title{
Developing a risk management system and assessing the effectiveness of integrated risk management in the space rocket sector
}

\author{
Alexander Sobol ${ }^{1}$, and Oleg Fadeev ${ }^{1, *}$ \\ ${ }^{1}$ Gazprombank, 16, Building 1, Nametkina str., 117420, Moscow, Russia
}

\begin{abstract}
The article discusses the formation of the system of risk management and evaluation of the effectiveness of integrated project risk management in the space rocket sector. The classification of the integrated project risks for knowledge-based enterprise in the space rocket sector and credit institution was made. The main methods of project risks evaluation, which can be applied in the space rocket sector, are described. The scheme of integrated project risk management was made on the basis of the life cycle approach when implementing projects in the space rocket sector. When implementing project risks in the space rocket sector, an enlarged scheme of the Regulations on Integrated Project Risk Management System, was developed. An issue of integrated risk management in the space rocket sector using a system of measures being named the "Value-at-Risk" (VaR) was reviewed. It was concluded that there was a need for project implementation in the space rocket sector using a complex, effective, and integrated system of risk management.
\end{abstract}

At present, we observe the active development of scientific and technical progress in many areas and sectors, including both the military/state and civilian sectors. Technologies that, as previously seemed, can be realized and are applicable only in the future are now actively involved and used in our daily lives.

For example, electric vehicles are gaining increasing popularity among car owners, which are designed and manufactured by major auto companies such as Toyota, BMW, Tesla, Nissan, Volvo, etc. They have a number of advantages such as environmental friendliness, safety, high engine efficiency, and cheaper cost of driving in comparison with the internal combustion engine [6].

In the rocket and space complex (RSC), we can see the same progress in the development of new technologies and active implementation of projects in both the public and commercial sectors. Such an acceleration in the development of the RSC and its new technologies with high costs stipulates and requires rational approach to the issue of risk assessment and management. In turn, the financing of projects on a commercial basis allows to expand the outlook of research in the RSC. The main purpose of attracting commercial capital and companies for the implementation of projects in the RSC is the

* Corresponding author: Oleg.Fadeev@gazprombank.ru 
guaranteed delivery of goods, the possibility of using independent access to outer space, effective expenditures, and financial control over the use of funds. This can all be achieved through an optimal set of financial, technical, organizational, and human resources associated with an effectively built risk assessment and management system. For example, the American engineer, scientist, and entrepreneur Ilon Mask went down in history when his company Space Exploration Technologies (SpaceX) became the first private company that docked the spacecraft to the international space station, successfully landed a Falcon 9 rocket on the offshore platform, and lowered the cost of the project [7].

Increased activity in the commercial activities of the RSC in the United States, Europe, Russia, China, and India clearly demonstrate the need for civilian space services and gives a clear signal about the need for space development in general. The creation and operation of unmanned aerial vehicles also speaks in favor of this trend. If they were previously used primarily in the state and defense complexes, now their civilian application in the civil sector is developing more actively [8].

The implementation of the project in the RSC is always connected with risks, which can be technological, financial, legal, personnel, and many others. The onset of a risk or a group of risks is possible at all phases of the life cycle of any project. Given the difficult situation that has recently taken shape in the political arena and in the Russian economy, the possibility of the onset of project risks in the RSC is significantly increasing. Risk situations can begin with the design of a spacecraft and end at the stage of operating the facility. In the authors' opinion, the objective of the project in the RSC is the production and sale of goods or services of rocket and space technology, space infrastructure facilities, innovative space technologies, provision of services for launching space objects, as well as operating existing facilities and infrastructure in the RSC for profit or for national security purposes.

The result of a project in the RCM is the obtaining of high-tech products or services that are intended for all interested consumers in the corporate or public sectors on a fee basis. In addition to the initiator and the investor, individuals and legal entities participate in the project at the time of its implementation; they have a number of duties, such as designing the facility, its development, doing preparatory work, as well as production, transportation, insurance, management, control and sales of the product or service.

The peculiarities of projectы in the RSC are a high degree of novelty, the quality of the product or service, the uniqueness of the samples produced, the use of high technologies, high costs, complexity of business processes, long terms, and impressive amounts of financing. All this requires increased attention on the part of managers and obliges project managers to create and implement an adequate and effective risk management system.

In order to correctly identify, systematize, evaluate, manage, and control project risks, it is necessary to classify them, that is, to distribute them to specific groups in accordance with a certain characteristic. In this case, such a factor is the specificity of projects in the RSC.

A conceptual and integrated classification of project risks in the RSC determines the place of each risk and creates an opportunity for effective application of management and risk management methods. Planned and implemented activities will allow to effectively apply the accumulated experience in the implementation of projects in the RSC in the future. They will also positively affect how project participants achieve their goals.

In the opinion of the authors, it is advisable to formulate a classification of project risks that would take into account the features of projects in the RSC, as well as would become fundamental and integrated for the main project participants. More than that, such a classification should be mobile and flexible in changing external and internal conditions, additionally being able to implement the principles of project risk management. 
The main reasons for the occurrence of risks and, as a consequence, increasing project costs are the business processes and areas of risk management. Business processes can be divided in different ways, but it is important to classify them within the project from the position of maximum identification for all project participants.

The authors propose to develop a classification of integrated project risks for initiators of the project in the RSC - a credit institution, a knowledge-intensive enterprise, and a project investor (Graph 1). 


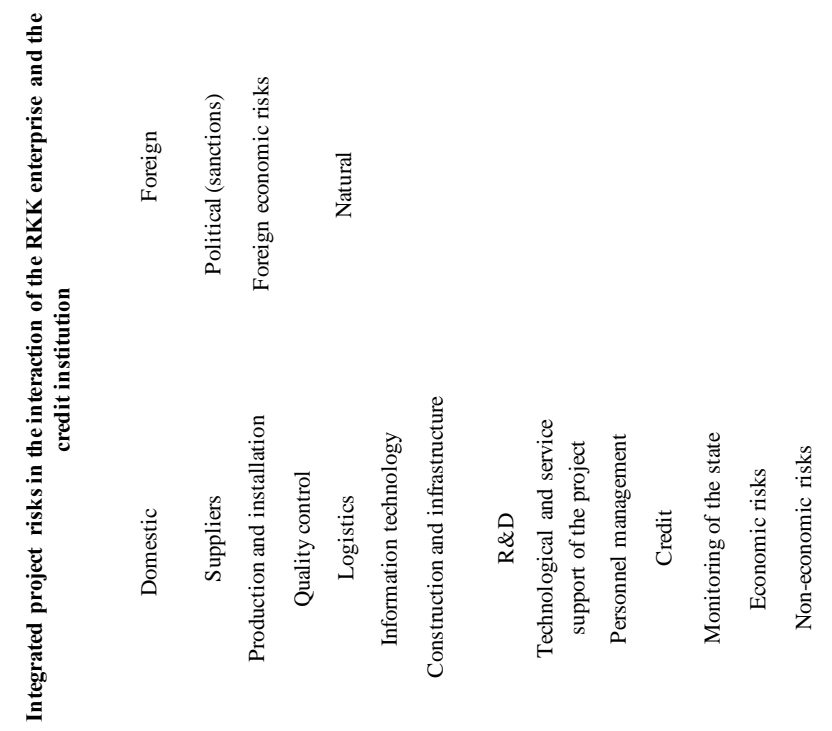

\|\|$\left\|\frac{1}{\|n\|}\right\|$

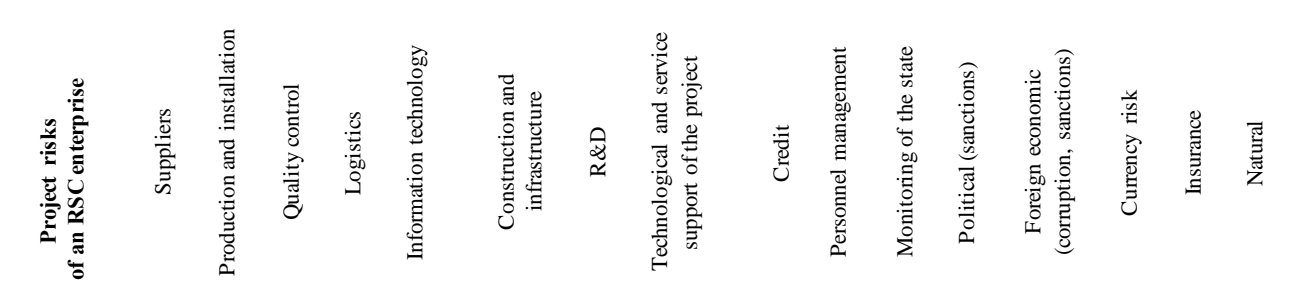

Fig. 1. Classification of integrated project risks in the RSC. 
Development of an integrated risk classification in the interaction of RSC enterprises and lending institutions is one of the important tasks in managing integrated project risks, the solution of which will provide an opportunity to balance risks by sources of threats, management principles, responsibility centers. It will also allow to develop and form methodological bases and a flexible system of risk management. Having developed an integrated risk classification, project managers can reliably establish the individual value of each risk, conduct its analysis and assessment, creating elements of an effective risk management system. To improve the quality of project risk management, it is necessary to effectively assess and manage independent and unrelated risks, paying detailed attention to many risk factors that are interrelated and correlated. In each specific case, project risks will be classified taking into account the specifics of the industry, its scale, technologies chosen, the country of implementation, and other features of a particular project. After classifying integrated project risks in the RSC, this is necessary to proceed to their assessment [2].

Estimating a project risk in the RSC is a set of measures that allow to forecast the possibility of obtaining additional profit or a certain amount of damage from the risk and erroneous coming from untimely management decisions. The rational organization of the project and an integrated approach to the assessment and management of project risks can be achieved only through the full use of methods for assessing project risks, their management and monitoring, taking into account the impact of internal and external factors.

Development of projects in the RSC, assessment of their effectiveness, and management are important and inextricably linked among themselves components of project risk management. An integrated approach to the organization of project risk management in the interaction of RSC enterprises and lending institutions should be implemented using both known and developed (adapted) methods in the implementation and management of projects.

Scientific and professional literature describes the methods for assessing project risks in detail, but their number is not always sufficient for a more complete and accurate analysis of the risks of space projects. Let's look at the basic methods for assessing project risks and develop methods for assessing and managing project risks in the interaction of RSC enterprises and lending institutions. The main methods of project evaluation include expert, statistical methods, as well as quantitative and qualitative assessment methods (Table 1) [2].

Table 1. Basic methods for assessing project risks.

\begin{tabular}{|c|l|l|l|}
\hline No & \multicolumn{1}{|c|}{ Method } & \multicolumn{1}{|c|}{ Features } & \multicolumn{1}{c|}{ Application area } \\
\hline 1 & Expert methods & $\begin{array}{l}\text { A complex of logical and } \\
\text { mathematical-statistical procedures for } \\
\text { processing information provided by an } \\
\text { expert/group of experts }\end{array}$ & $\begin{array}{l}\text { Risk identification, } \\
\text { ranking, quantitative, } \\
\text { and qualitative } \\
\text { assessment }\end{array}$ \\
\hline 2 & $\begin{array}{l}\text { Statistical } \\
\text { methods }\end{array}$ & $\begin{array}{l}\text { Use of statistical criteria for measuring } \\
\text { the magnitude of the risk }\end{array}$ & $\begin{array}{l}\text { Quantitative risk } \\
\text { assessment }\end{array}$ \\
\hline 3 & SWOT-analysis & $\begin{array}{l}\text { Reflects the strengths, weaknesses of } \\
\text { the project, as well as the opportunities } \\
\text { and threats associated with it }\end{array}$ & $\begin{array}{l}\text { Expert identification } \\
\text { and risk assessment }\end{array}$ \\
\hline 4 & Rose (spiral) of risks & $\begin{array}{l}\text { Illustrates expert evaluation of design } \\
\text { risks }\end{array}$ & Risk ranking \\
\hline 5 & $\begin{array}{l}\text { Method of analogies or } \\
\text { conservative forecasts }\end{array}$ & $\begin{array}{l}\text { A study of the accumulated experience } \\
\text { in analog projects with a view to } \\
\text { calculating possible losses }\end{array}$ & $\begin{array}{l}\text { Risk assessment of } \\
\text { frequently recurring } \\
\text { projects }\end{array}$ \\
\hline 6 & Interest-rate method & The increase in the risk-free rate of & Additional \\
\hline
\end{tabular}




\begin{tabular}{|c|l|l|l|}
\hline & adjusted for risk & $\begin{array}{l}\text { interest on the amount of the risk } \\
\text { premium (risk premium) }\end{array}$ & $\begin{array}{l}\text { consideration of risk } \\
\text { factors in calculating } \\
\text { the effectiveness of } \\
\text { the project }\end{array}$ \\
\hline 7 & Critical value method & $\begin{array}{l}\text { Determination and establishment of } \\
\text { critical values / variables (factors) that } \\
\text { affect project risk }\end{array}$ & $\begin{array}{l}\text { Monitoring of risks in } \\
\text { the process of project } \\
\text { management }\end{array}$ \\
\hline 8 & "Decision Trees" & $\begin{array}{l}\text { Method of decision-making when } \\
\text { choosing one of the alternative options } \\
\text { and forming an optimal strategy }\end{array}$ & $\begin{array}{l}\text { Risk analysis at the } \\
\text { project planning stage. } \\
\text { Project management }\end{array}$ \\
\hline 9 & Sensitivity analysis & $\begin{array}{l}\text { Analysis of the behavior of the project's } \\
\text { benchmarks as a result of a change in } \\
\text { one risk factor }\end{array}$ & $\begin{array}{l}\text { Quantitative Risk } \\
\text { Analysis }\end{array}$ \\
\hline 10 & Scenario Analysis & $\begin{array}{l}\text { Analysis of the behavior of the } \\
\text { project's benchmarks as a result of } \\
\text { changes in the range of risk factors } \\
\text { (multifactor analysis) }\end{array}$ & $\begin{array}{l}\text { Quantitative approach } \\
\text { in risk analysis and } \\
\text { management }\end{array}$ \\
\hline 11 & Simulation modeling & $\begin{array}{l}\text { Use of a numerical risk assessment } \\
\text { Quantitative } \\
\text { assessment of integral } \\
\text { risk in general }\end{array}$ \\
\hline
\end{tabular}

Expert methods for assessing project risks are those methods that are based on the knowledge and experience of individual experts in a particular field. These methods are suitable in situations where the required information on the outcomes or the likelihood of their occurrence is absent, insufficient, or not formalized [2].

The general procedure for assessing project risks using expert methods can consist of several stages: an analysis of the assignment to experts in risk assessment of the project; organizational and methodological preparation for conducting an expert evaluation; selecting experts on the basis of general erudition, logical and analytical thinking, knowledge and skills in a certain professional field; carrying out expert predictive studies or conducting predictive assessments (the main forms of expert evaluation are the rank method, the method of scale scores, the method of pairwise comparisons); processing, analysis of forecast research results and provision of information to customers for management decisions.

Statistical methods use statistical criteria for measuring the risk value being calculated on the basis of reliable and complete statistical information, for example, such as the average expected value and variability of the possible result [2].

Conducting a qualitative analysis of project risks begins with their identification, analysis, and investigation of possible causes of occurrence. Further, a cost evaluation of the possible consequences of damage from the implementation of identified risks is carried out, and measures to reduce them are being developed. This is a specific feature of a qualitative approach to researching project risks. The quantitative analysis of project risks includes the conducted qualitative analysis and the initial data of the project business plan. The task of quantitative analysis is the numerical measurement of the changing project factors that are checked for risk and the behavior of the project effectiveness criteria. Quantitative analysis is based on methods of mathematical statistics [1].

Most other known methods of assessing project risks have their advantages and disadvantages. When implementing projects in the RSC, this is the most effective and appropriate to use a systemic and integrated approach with a set of different methods for assessing project risks, promptly introducing additional methods for managing or excluding those that have lost relevance. An equally important process in implementing the project and creating a risk management system is project risk management. 
Project management in the RSC is carried out through life-cycle phases, namely in the pre-project phase, design, and operation phases [3]. The process of creating and adapting a management mechanism for integrated project risks can be represented by a set of integrated measures implemented at all levels of project management and integrated into three main phases (Graph 2).

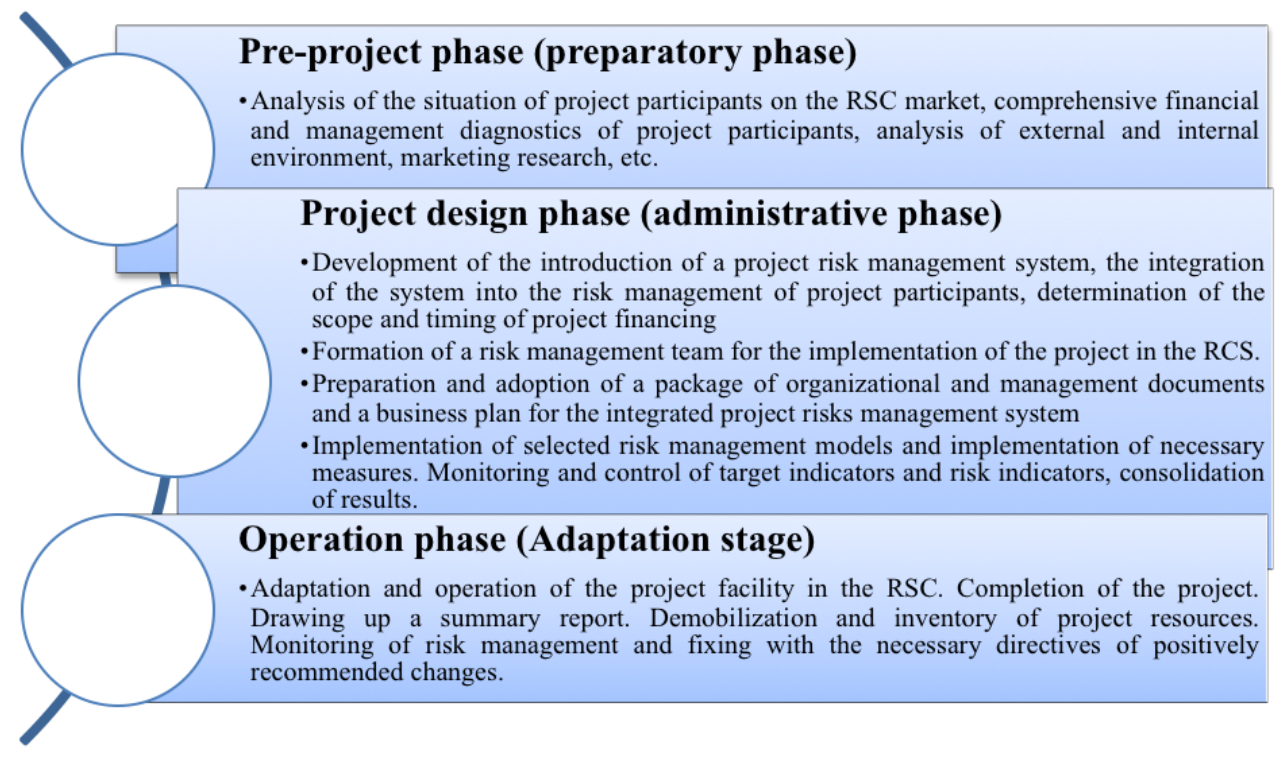

Fig. 2. The scheme for managing integrated project risks for the life cycle phases for the implementing projects in the RSC.

The first stage, preparatory, will be related to the preliminary work and the preparation of forming a management system for integrated project risks. The work plan is developed by the specialized unit for project risk management and approved by project managers. It can consist of detailed elaboration of concrete stages of work, regulation of terms, definition of job responsibilities of performers and necessary technological, financial, intellectual and other resources.

At the second stage, managerial, project risk management systems are developed and implemented, the system integration into the risk management of the project participants occurs, the amount and timing of project financing are determined, the formation of the team occurs, etc.

The third stage, adaptation, includes the adaptation and operation of the project facility in the RSC and risk management systems.

The stages of creating a system for managing integrated project risks in the RSC developed by the authors are universal and can be used by other market participants. The proposed concept will allow them to optimize the process of managing project risks. An important and integral part of risk management in the implementation of projects in the $\mathrm{RSC}$ is the subsequent monitoring and evaluation of the effectiveness of project risk management. The researches carried out by the authors show that the creation and implementation of a new independent structural division of risk management or the combination of specialized specialists on the basis of an already existing service are the most rational when implementing projects in the RAC.

After the newly established structural unit begins its activity, its employees form and adapt the Regulation on the Integrated Risk Management System for the implementation of projects in the RSC. The developed Regulation is coordinated and approved by the 
stakeholders of the project. The integrated scheme of the Regulation on the Management System for Integrated Project Risks in the Implementation of Project Risks in the RSC is presented by the authors in Figure 3.

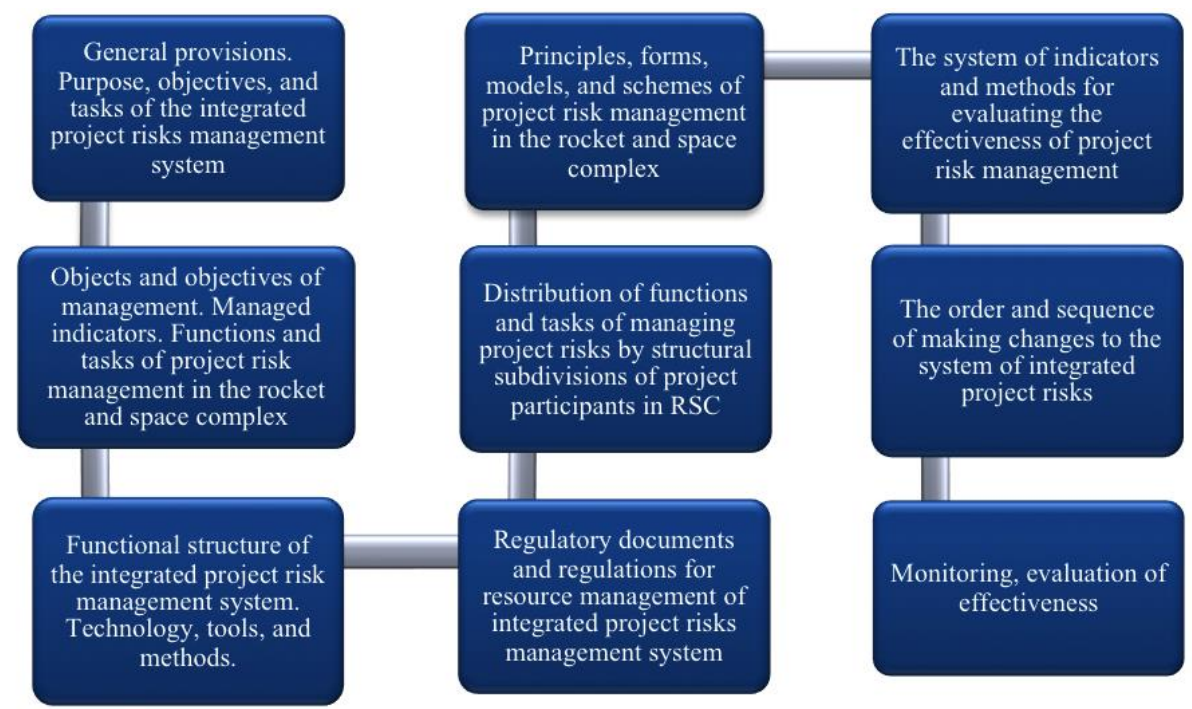

Fig. 3. The enlarged scheme of the Regulation on the Integrated Project Risk Management System in the RSC.

Having the Regulation on the Integrated Project Risk Management System being completed, the authorized risk management division carries out work on its adaptation and implementation in the existing or planned project in the RSC, and also compares and consolidates reports for project managers on the basis of which they make management decisions in the process of implementation and project management. To provide prompt, reliable, and high-quality information, it is necessary to analyze and evaluate the effectiveness of the integrated project risks management system after its implementation and do it in a timely manner and within the framework of the business plan.

As applied to this work, the assessment of the effectiveness of managing integrated project risks in the RSC means that there is the need to identify and justify the sources, factors, indicators, and components of the management effectiveness of integrated project risks. Evaluation of the effectiveness of managing integrated project risks in the implementation of projects in the RSC is based on the following main components:

- development and implementation of the Regulation on the Integrated Project Risk Management System in the RSC;

- assessment of the effectiveness of implementation and adaptation of the integrated risk management system in the implementation of projects in the RCM;

- assessment of the effectiveness of managing integrated project risks through an event system called Value-at-Risk or VaR [1].

Given the specifics of projects in the RSC, according to the authors, the following two methods for assessing the effectiveness of implementation and adaptation of the integrated project risk management system can be singled out separately.

1. A Comprehensive method based on the definition of additional net present value $(\triangle \mathrm{NPV})[4]$, being obtained from the introduction and adaptation of the integrated project risks management system. 
2. A local method that involves determining the particular effects from the introduction and adaptation of the integrated project risk management system as the difference between the increase in the financial result and the costs of implementing this system, respectively.

The most frequent (especially in the process of implementation and adaptation of the risk management system or the implementation of projects in the RSC) and preferred method is the integrated method. However, in some cases, when the transition to cost principles of risk management affects only a number of objects or individual business processes and units, for example, the application of a local method is also possible.

When implementing a comprehensive method for assessing the effectiveness of implementation and adaptation of the project risk management system, it is appropriate to use an integrated calculation method, the sequence of implementation of which consists of three main stages:

- Calculating the net present value (NPV) when implementing the project prior to the implementation of the integrated risk management system;

- Calculating the net present value (NPV) when implementing the project after the implementation of the integrated risk management system;

- Degerming the difference between the NPVafter and NPVbefore the implementation of the integrated project risk management system.

Evaluation of the effectiveness of the implementation and adaptation of the integrated risk management system in the implementation of projects in the RSC is carried out by comparing the implementation of the project, which involves the implementation of a system with a limited implementation or a rejection.

In general, the calculation formula can be represented in the following form:

NPVproject = NPVafter $(n)-$ NPVbefore (n), where NPVafter (n) is the cash flow balance for $n$ steps when considering the option of introducing an integrated risk management system; NPVbefore (n) is the cash flow balance for $\mathrm{n}$ steps when considering the option that does not provide for the introduction of an integrated risk management system.

Thus, the net present value of introducing and adaptating the integrated project risk management system is equal to the difference between cash flows in the "after" and "before" options, which are discounted using the discount rates for each option, minus the initial investment.

Evaluation of the effectiveness of implementing the integrated project risk management system in the RSCM should be carried out continuously for the duration of the project planning and implementation. It is aimed at improving the effectiveness of project risk management, provides for comprehensive continuous monitoring, and involves an assessment of risk management that can be implemented through a system of activities called Value-at-Risk или VaR [2].

Qualitatively, VaR can be defined as the sum of losses in a project with a given small probability for a limited period of time. In fact, VaR is an integrated approach that combines elements of statistical and analytical modeling.

$\mathrm{VaR}$ is a monetary assessment of possible losses of project participants in case of unfavorable introduction and adaptation of the integrated project risks management system and, as a result, possible liquidation of the project. One of the requirements of the VaR calculation is the assumption that the business plan for implementing the integrated project risk management system remains unchanged during the estimated period (for example, day, week, etc.).

The entire range of VaR models can be divided into four categories.

1. Models based on the variational-covariance matrix;

2. Models built on the principle of historical modeling;

3. Models built using the Monte Carlo method; 
4. Models based on the theory of estimating the extreme values of distributions.

Each category includes a large number of methods, the differences between which are determined by the degree of simplification of the real market situation and a set of initial assumptions.

The approach used to construct the model on the basis of the variational-covariance matrix is also called the analytical method of calculating VaR. This approach assumes that the change in the project cost is distributed according to the normal law, and the calculation of the VaR multicomponent components of the integrated project risk management system requires knowledge of the correlation between these components.

Models built on the principle of historical modeling are non-parametric and are based on the assumption of stationarity of the market in the near future. In this case, the method uses the previous price parameters to calculate the hypothetical distribution of periodic changes in the components of the integrated project risk management system in the RSC.

The Monte Carlo method, on the contrary, uses detailed statistical information and mathematical methods to generate as many variants of scenarios as possible. Unlike historical modeling, in the Monte Carlo method, the price changes of the components of the integrated project risk management system are generated in a pseudo-random manner in accordance with the specified parameters [5].

The fourth category of $\mathrm{VaR}$ calculation models is the method of estimating the extreme values of the efficiency distribution from the introduction and adaptation of the integrated project risk management system in the RSC. In the process of calculation, VaR is determined as the so-called "tail index," which estimates the nature of the distribution of the values of the variable at the edges of the basic distribution.

If none of the models are suitable for assessing the effectiveness of the implementation and adaptation of the integrated project risk management system, the use of expert estimates of the $\mathrm{VaR}$ indicator is allowed, which is to be conducted by the risk department being responsible for implementing the risk system in the RSC project.

It should be noted that the formation of tools and the assessment of the effectiveness of the implementation and adaptation of the integrated project risk management system in the $\mathrm{RSC}$ is not limited to the procedures described above. In particular, the risk manager should pay attention to the correctness of the chosen strategy, the relevance and reliability of the data used, as well as the correct distribution of the roles of project participants.

The research conducted by the authors suggests that the formation of a risk management system and the assessment of the effectiveness of managing integrated project risks in the implementation of projects in the RSC is one of the priority tasks that requires increased attention from project managers. The solution of this problem is possible through the use of an integrated approach in the classification, evaluation, management, and continuous monitoring of project risks. All the variety of assessment and risk management methods contribute to the creation of a fundamental, integrated, organic, and structured risk management system for managing integrated project risks, and also serves as a basis for making effective managerial decisions in the course of the project implementation and the key to achieving its objectives by its participants.

\section{References}

1. V. M. Akhundov, A. I. Sobol, Financial risk (ISAA Publishing House, Moscow, 2000)

2. A. G. Badalova, A. I. Sobol, Theoretical and methodological foundations and methodological tools for assessment and risk management of financial and nonfinancial organizations (Dobroe Slovo Publishing House, Moscow, 2015) 
3. Project Management Institute, A guide to the project management of the knowledge body (PMI, Newtown Square, 2013)

4. E. P Zharkovskaya, B. E. Brodsky, I. B. Brodsky, Anti-crisis management (Omega-L, Moscow, 2014)

5. E. M. Korolkova, Risk management: project risk management: a textbook for students of economic specialties (Tambov State Technical University, 2013)

6. Electric vehicles of other manufacturers (http://autotesla.ru/category/other-elektrokar)

7. The American launch vehicle Falcon 9 (http://tass.ru/info/3262897)

8. Rating of manufacturers of unmanned passenger cars (http://bespilotnik.org/company/ news/2016/reyting_bpla). 